\title{
44 PESTICIDE EXPOSURE AND SCREEN-IDENTIFIED NEUROPSYCHIATRIC DISEASE IN BRITISH SHEEP FARMERS
}

Andrew Povey, Roseanne McNamee, SJ Stock, G Watkins, F Creed, A Burns, D Neary, Raymond Agius University of Manchester, Manchester, UK

10.1136/oemed-2011-100382.44

Objectives Chronic low dose pesticide exposure, especially to organophosphates (OPs) has been associated with ill-health particularly in sheep farmers but in the absence of overt acute toxicity the epidemiological evidence linking chronic ill-health to such exposures is weak. Our aim was to determine whether neuropsychiatric disease was associated with pesticide exposure in sheep farmers.

Methods 18958 British farmers from the 1970s were identified using contemporaneous records held by the National Farmers' Union, Sheep and Cattle Associations and through Shepherd's Guides. Each farmer was sent a health and occupational questionnaire. The prevalence of screen identified depression, dementia, Parkinsonism and neuropathy was determined using previously published algorithms. Associations between work activities, handling the pesticide concentrate, and screen identified ill-health were determined after adjustment for demographic variables.

Results Screen-identified ill-health was associated with the somatic symptom severity score and ever seeking advice for pesticide poisoning. Handling the pesticide concentrate was associated with screen-identified Parkinsonism $\left(\mathrm{OR}_{\text {adj }}\right.$ 1.76, $95 \%$ CI 1.06 to 2.92$)$ and to a lesser extent with neuropathy $\left(\mathrm{OR}_{\mathrm{adj}} 1.58,95 \% \mathrm{CI} 0.96\right.$ to 2.60$)$ but not depression or dementia. After excluding those participants who had sought advice for pesticide poisoning, risks for Parkinsonism and neuropathy remained elevated but were no longer significant. After stratification by somatic symptom severity score, associations were found only in farmers with low scores.

Conclusions Results are consistent with the a priori hypothesis linking chronic low dose exposure to ill-health but require confirmation using more precise measures of exposure and outcome. Somatisation does not appear to play an important role in this population. 